BMJ Open

Diabetes

Research

\& Care

\title{
Developing priorities to achieve health equity through diabetes translation research: a concept mapping study
}

\author{
Allison Phad (D) , ${ }^{1}$ Shelly Johnston, ${ }^{1}$ Rachel G Tabak (D) , ${ }^{2}$ Stephanie Mazzucca, ${ }^{2}$ \\ Debra Haire-Joshu ${ }^{3,4}$
}

To cite: Phad A, Johnston S, Tabak RG, et al. Developing priorities to achieve health equity through diabetes translation research: a concept mapping study. BMJ Open Diab Res Care 2019;7:e000851. doi:10.1136/ bmjdrc-2019-000851

- Additional material is published online only. To view please visit the journal online (http://dx.doi.org/10.1136/ bmjdrc-2019-000851).

Received 23 August 2019 Revised 17 October 2019 Accepted 3 November 2019

Check for updates

C) Author(s) (or their employer(s)) 2019. Re-use permitted under CC BY-NC. No commercial re-use. See rights and permissions. Published by BMJ.

${ }^{1}$ Washington University Center for Diabetes Translation Research, Washington University in St. Louis, St. Louis Missouri, USA

${ }^{2}$ Prevention Research Center in St. Louis, Washington University in St. Louis, St. Louis, Missouri, USA

${ }^{3}$ The Brown School, Washington University in St. Louis, St. Louis, Missouri, USA

${ }^{4}$ Washington University School of Medicine, Washington University in St. Louis, St. Louis, Missouri, USA

Correspondence to

Allison Phad;

allisonphad@wustl.edu

\section{ABSTRACT}

Introduction The goal of diabetes translation research is to advance research into practice and ensure equitable benefit from scientific evidence. This study uses concept mapping to inform and refine future directions of diabetes translation research with the goal of achieving health equity in diabetes prevention and control.

Research design and methods This study used concept mapping and input from a national network of diabetes researchers and public health practitioners. Concept mapping is a mixed-method, participant-based process. First, participants generated statements by responding to a focus prompt ("To eliminate disparities and achieve health equity in the prevention and treatment of diabetes, research should..."). Participants then sorted statements by conceptual similarity and rated each statement on importance and feasibility (Likert scale of 1-5). A cluster map was created using multidimensional scaling and hierarchical cluster analysis; statements were plotted by average importance and feasibility.

Results Ten clusters were identified containing between 6 and 12 statements from 95 total generated statements. The ranges of average importance and feasibility ratings for clusters were fairly high and narrow (3.62-4.09; 3.103.93 , respectively). Clusters with the most statements in the "go-zone" quadrant (above average importance/ feasibility) were community and partner engagement $(\mathrm{n}=7)$, dissemination and implementation principles $(\mathrm{n}=4)$ and enrichment and capacity building $(\mathrm{n}=4)$. Clusters with the most statements in the "innovative-targets" quadrant (above average importance, below average feasibility) included next generation interventions $(\mathrm{n}=6)$, policy approaches $(\mathrm{n}=4)$, and interventions for specific populations $(\mathrm{n}=4)$.

Conclusions This study created a framework of 10 priority areas to guide current and future efforts in diabetes translation research to achieve health equity. Themes rated as highly important and feasible provide the basis to evaluate current research support. Future efforts should explore how to best support innovative-targets, those rated highly important but less feasible.

\section{INTRODUCTION}

In the USA, 1 in every 11 people are diagnosed with diabetes and 84.1 million people have prediabetes. ${ }^{1}$ Despite advances in diabetes research, there remains a gap between scientific evidence, real-world

\section{Significance of this study}

What is already known about this subject?

- The gap between scientific evidence and real-world application of high-quality care and prevention is especially evident among communities experiencing disparities in diabetes burden who have been less likely to benefit from translation of these breakthroughs.

\section{What are the new findings?}

- This study used the concept mapping methodology and a national network of diabetes researchers and public health practitioners to create a framework of 10 priority areas to guide future efforts in diabetes translation research to achieve health equity.

How might these results change the focus of research or clinical practice?

- Themes rated as highly important and feasible provide the basis to evaluate current research efforts;

- Future efforts and research should explore how to best support innovative-targets, themes rated highly important but less feasible, to advance the field of diabetes translation research.

application and impact at a population level. This gap is evident in both the generation of quality, evidence-based interventions for priority populations and the implementation of high-quality care and prevention practice in communities experiencing health disparities. $^{1-3}$ Eliminating disparities in diabetes burden requires innovative solutions and the adaptation and dissemination of evidencebased approaches to real-world settings. ${ }^{4}$ To promote translation of research to practice in ways that promote health equity, rather than reinforce disparities, changes to research methods are needed at multiple levels. For example, efficacy trials including priority populations, who have been historically omitted from this research, could reduce the need for adaptation as interventions are translated to real-world practice. ${ }^{5}$ These approaches will aid in achieving the goal of 
diabetes translation, which is to advance research along the translational continuum and ensure equitable population benefit from scientific evidence. ${ }^{3}$

The Washington University Center for Diabetes Translation Research (WU-CDTR) is one of eight centers funded by the National Institute of Diabetes and Digestive and Kidney Disease (NIDDK) to enhance scientific progress through support of rigorous translation research aimed at the prevention and treatment of diabetes and related conditions. ${ }^{6-8}$ Funded in 2011, the WU-CDTR supports a national network of investigators conducting translation research in real-world settings with a goal of eliminating disparities in diabetes to achieve health equity. The WU-CDTR offers investigators services needed to conduct cutting edge translational research. Thus, it is important to systematically assure these services are timely and relevant in supporting current and future diabetes translational research.

Concept mapping has been used as an effective strategy to build research agendas in multiple content areas including policy and physical activity, ${ }^{9}$ food access in rural communities, ${ }^{10}$ chronic disease prevention, ${ }^{11}$ and dissemination and implementation science. ${ }^{12}$ Concept mapping is a mixed-method, multistep process of idea generation and organization that relies on input from key stakeholders. ${ }^{13}$ The end product is a visual representation, a concept map, of the thoughts of the whole group and is often used in planning and evaluation. ${ }^{13} \mathrm{In}$ this study, we use concept mapping to inform and refine future directions of diabetes translation research with the goal of achieving equity in diabetes prevention and control.

\section{RESEARCH DESIGN AND METHODS}

\section{Concept mapping process}

In this study, a research team of five (AP, SJ, RT, SM, $\mathrm{DHJ}$ ) oversaw all aspects of the concept mapping process. Concept mapping is a participant-based process and consists of several stages: identify relevant stakeholders and develop the focus prompt; generate ideas through brainstorming; structure ideas through sorting and rating; analyze data and create the cluster map and other visual representations; and interpret and use results. Idea generation through data analysis was completed using Concept Systems Global MAX software. ${ }^{14}$

\section{Identifying stakeholders and developing the focus prompt}

First, stakeholders were identified using the WU-CDTR membership network consisting of 90 transdisciplinary diabetes researchers at 27 universities across 20 states. For a practitioner perspective, we sought input from the National Association of Chronic Disease Directors, consisting of 7000 chronic disease professionals working in a variety of settings (ie, state, local health department, nonprofit) ${ }^{15}$ and identified practitioners with a diabetes focus. We identified 140 potential participants engaged in diabetes work for recruitment.
The research team developed the focus prompt with input from established experts in diabetes translation research and concept mapping and familiar or associated with the WU-CDTR. Suggested focus prompts were generated by the research team, reviewed by experts, and revised to assure appropriate focus and generation of a wide variety of ideas.

\section{Idea generation, brainstorming}

To begin idea generation, an email invitation was sent to all potential participants, which directed them to the Concept Systems Global MAX ${ }^{14}$ project site. Within the site, participants could see the focus prompt and were asked to complete the statement "To eliminate disparities and achieve health equity in the prevention and treatment of diabetes, research should..." Respondents were able to enter as many statements as they desired and could view all previous statements generated.

Two members of the core research team (AP, SJ) synthesized the statement list as recommended. ${ }^{13}$ Statements were edited for clarity and to ensure only one idea was represented in each statement. In addition, repetitive statements were removed to produce a final list that is manageable for the sorting and rating stages; 100 or fewer statements representing unique ideas are recommended. ${ }^{13}$

\section{Structuring of ideas}

Three activities provided structure to the final list of statements: sorting, rating on feasibility, and rating on importance. All participants invited to the brainstorming stage were invited to complete the sorting and rating exercises. During the sorting exercise, participants were asked to create piles, or group statements, based on their similarity. Participants could decide any way to group the statements with the following guidelines: statements cannot be put into one pile, all statements cannot be sorted into their own separate piles, and each statement can be placed only in one pile. Participants were also asked to name each pile based on the similarities or themes of the statements sorted to that pile.

Next, participants rated each statement based on feasibility (Rate how feasible each statement is to implement or incorporate into diabetes research, from 1 "Not feasible" to 5 "Extremely feasible") and importance (Rate each statement on how important you think it is in order for research to achieve health equity in the prevention and treatment of diabetes, from 1 "Not important" to 5 "Extremely important") in achieving health equity in diabetes.

\section{Data analysis and creation of cluster map}

A cluster map was developed using multidimensional scaling and hierarchical cluster analysis. As part of these methods, first a similarity matrix is created consolidating sorting data from all participants. Multidimensional scaling then creates a point map with each statement represented as a separate point on a two-dimensional plane; the distance between each point represents how 
often statements were sorted together, with more similar statements placed closer on the map. ${ }^{13}{ }^{16}$ Hierarchical cluster analysis then groups points together to reflect similar concepts in each cluster. ${ }^{13}$ The research team examined several iterations of the cluster map, working down from 15 clusters, to determine the best representation of the underlying point-map. Each cluster was examined for uniformity of ideas and along with statements' bridging value, which indicate if a statement is "anchored" to that map position and is a good representation of others in its vicinity. ${ }^{13}$

The diagnostic statistic produced in multidimensional scaling is the stress index, measuring the degree to which the point map is dissimilar from the similarity matrix. A lower stress index indicates a better overall fit; from a pooled analysis of concept mapping studies, the average stress value of concept mapping studies is $0.285(\mathrm{SD}=0.04$; $95 \%$ CI 0.205 to 0.365$).{ }^{13} 17$

Feasibility and importance rating data were averaged for each statement and by cluster. Ratings were overlaid with the cluster map to create cluster rating maps (not shown). A pattern match compared the feasibility and importance of each cluster and correlation of the two ratings within each cluster. Statements were plotted based on feasibility and importance ratings, creating a priority-quadrant plot that depicts the statements that are the most actionable. ${ }^{13}$

\section{Ethical statement}

This study was approved by the Washington University in St. Louis Institutional Review Board (IRB \#201812015). As part of the review, the Institutional Review Board approved the consent process. The consent process consisted of a written statement on the web-based software; participants selected "Accept" before continuing with participation.

\section{RESULTS}

The research team invited 140 individuals to participate in the brainstorming portion of the study, during which 63 participants generated 119 statements. Brainstorming was conducted anonymously; therefore, we cannot describe the demographics of the brainstorming participants. Based on similarity of ideas, the research team synthesized the initial list of 119 generated statements down to 95 unique ideas for participants to sort and rate. For example, we combined "Focus on addressing root causes of disparities in behaviors that lead to diabetes" with "Find ways to address the social determinants of diabetes and related health disparities."

In the structuring stages, 29 participants completed at least one of the three sorting and rating activities. An activity was considered complete for sorting if the participant sorted all statements; rating data were included if the participant rated at least 10 statements. Characteristics of the sorting and rating groups are described in table 1 . Overall, a majority of participants worked in

\begin{tabular}{|c|c|c|c|}
\hline & $\begin{array}{l}\text { All sorting } \\
\text { and rating } \\
\text { participants, } \\
n(\%) \\
n=29\end{array}$ & $\begin{array}{l}\text { Sorting } \\
\text { participants, } \\
\text { n (\%) } \\
n=25\end{array}$ & $\begin{array}{l}\text { Rating } \\
\text { participants, } \\
\text { n (\%) } \\
\text { n=26 }\end{array}$ \\
\hline \multicolumn{4}{|l|}{ Profession } \\
\hline Academia & $24(83)$ & $20(80)$ & $22(85)$ \\
\hline Healthcare & $2(7)$ & $2(8)$ & $2(8)$ \\
\hline $\begin{array}{l}\text { Public health } \\
\text { practitioners }\end{array}$ & $3(10)$ & $3(12)$ & $2(8)$ \\
\hline \multicolumn{4}{|l|}{ Years of experience } \\
\hline$\leq 10$ years & $7(24)$ & $6(24)$ & $6(23)$ \\
\hline$>10$ years & $22(76)$ & $19(76)$ & $20(77)$ \\
\hline \multicolumn{4}{|l|}{ Race/ethnicity } \\
\hline $\begin{array}{l}\text { American Indian or } \\
\text { Alaska Native }\end{array}$ & $1(3)$ & $1(4)$ & $1(4)$ \\
\hline $\begin{array}{l}\text { Asian or Pacific } \\
\text { Islander }\end{array}$ & $0(0)$ & $0(0)$ & $0(0)$ \\
\hline $\begin{array}{l}\text { Black or African } \\
\text { American }\end{array}$ & $3(10)$ & $2(8)$ & $3(12)$ \\
\hline $\begin{array}{l}\text { Hispanic or } \\
\text { Latino(a) }\end{array}$ & $2(7)$ & $1(4)$ & $2(8)$ \\
\hline $\begin{array}{l}\text { White, Hispanic/ } \\
\text { Latino(a) }\end{array}$ & $1(3)$ & $1(4)$ & $1(4)$ \\
\hline $\begin{array}{l}\text { White, non- } \\
\text { Hispanic/Latino(a) }\end{array}$ & $22(76)$ & $20(80)$ & $19(73)$ \\
\hline WU-CDTR member & $24(83)$ & $20(80)$ & $22(85)$ \\
\hline
\end{tabular}

WU-CDTR, The Washington University Center for Diabetes Translation Research.

academia $(83 \%)$, had over 10 years of experience in their field $(76 \%)$, and identified as White, non-Hispanic/ Latino $(76 \%)$.

The final cluster map is presented in figure 1 . Ten clusters were identified containing between 6 and 12 statements: (1) community and partner engagement, (2) enrichment and capacity building, (3) interventions for specific populations, (4) context specific interventions, (5) dissemination and implementation principles, (6) nontraditional settings and strategies, (7) cost and health economics, (8) innovative methods and metrics, (9) policy approaches, and (10) next generation interventions. Proximity of clusters suggests similarity of concepts. ${ }^{13}$ For example, figure 1 suggests that cost and health economics is more similar to policy approaches than it is to community and partner engagement. In regards to size, larger clusters indicate broader concepts while smaller clusters suggest a more narrow focus. ${ }^{13}$ For example, size suggests that enrichment and capacity building may have a wider range of ideas compared with cost and health economics. Table 2 shows examples of statements in each cluster with above average importance ratings (a complete list can be found in online supplementary appendix table 1). The final stress index is 0.3098 after 31 iterations.

The ranges of average importance and feasibility ratings were fairly high and narrow $(3.62-4.09 ; 3.10-3.93$, 

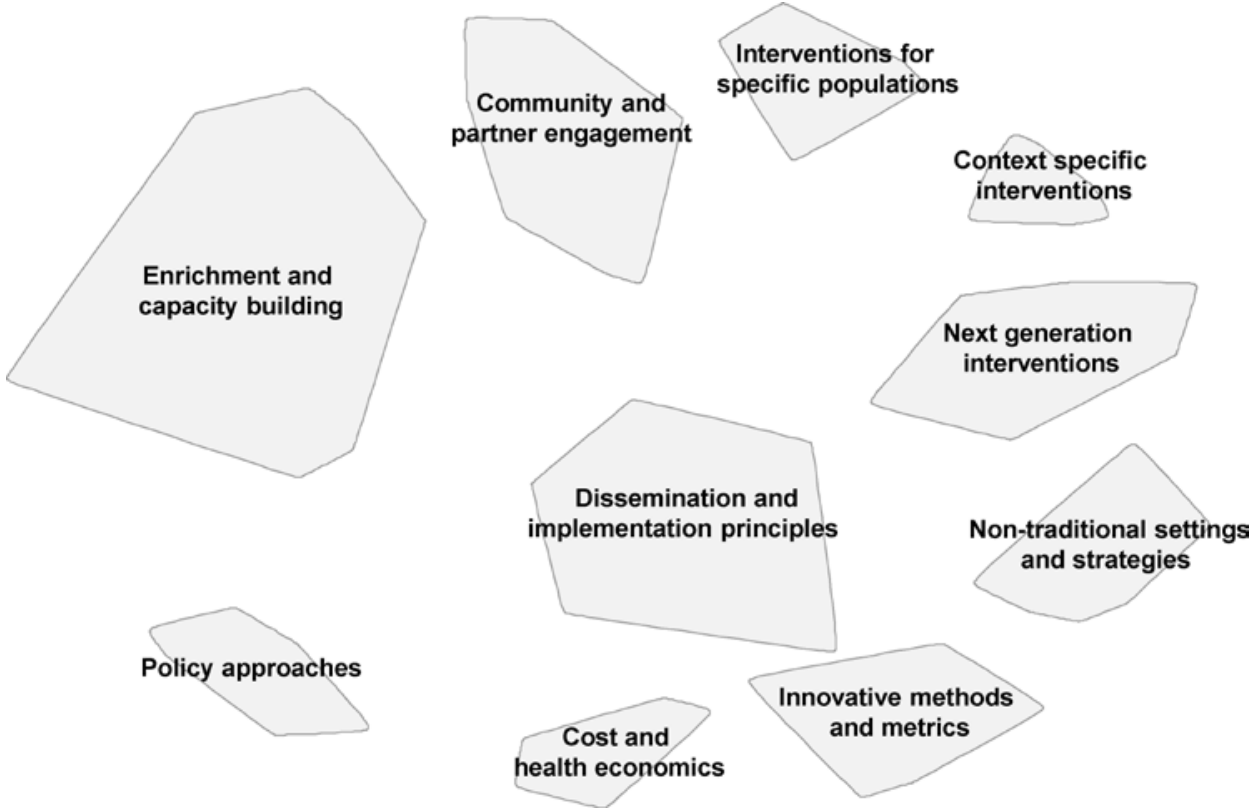

Figure 1 Cluster map of strategies to achieve health equity in diabetes research.

respectively). The pattern match diagram in figure 2 depicts the comparison of importance and feasibility rating for each cluster. Overall, most clusters were rated higher in importance than feasibility; nontraditional settings and strategies, and innovative methods and metrics were the only clusters with feasibility ratings greater than or equal to their importance ratings. Interventions for specific populations was ranked most important and nontraditional settings and strategies least important. Innovative methods and metrics was ranked the most feasible while policy approaches the least. The cluster policy approaches had the greatest difference between importance and feasibility ratings followed by next generation interventions, both rated as highly important with lower feasibility. The correlation between importance and feasibility ratings was $\mathrm{r}=-0.20$.

After plotting statements by average feasibility and importance ratings, statements fell into one of four priority quadrants: (I) high importance/high feasibility (gozone); (II) high importance/low feasibility (innovativetargets); (III) low importance/high feasibility; and (IV) low importance/low feasibility (see figure 3 ). Quadrant I is described as the "go-zone," defined as above average rating for both importance (3.91) and feasibility (3.65). For the purposes of this study, we are defined quadrant II as "innovative-targets," characterized by above average importance and below average feasibility.

The clusters with the most statements in the "go-zone" were community and partner engagement $(\mathrm{n}=7)$, dissemination and implementation principles $(\mathrm{n}=4)$, and enrichment and capacity building $(\mathrm{n}=4)$. Examples of these statements, characterized by high importance/high feasibility, are "Include the patient population so they are equal partners in research, clinical care, outreach and long term care," "Adopt a multidisciplinary approach," and "Develop provider and researcher capacity for conducting community-engaged research and addressing social determinants." The nontraditional settings and strategies, cost and health economics, policy approaches, and next generation interventions clusters each have only one statement in the "go-zone" quadrant (table 2).

The clusters with the most statements in the "innovative targets" quadrant included next generation interventions $(\mathrm{n}=6)$, policy approaches $(\mathrm{n}=6)$, and interventions for specific populations $(\mathrm{n}=4)$. Statements describe developing interventions that target the social determinants of health and address comorbidity; building sustainable solutions and increased resources in rural, tribal, and communities of color; and informing healthcare policy as it relates to cost and access.

\section{DISCUSSION}

The WU-CDTR used concept mapping as a tool to develop a conceptual framework to inform and refine future directions for diabetes translation research. Concept mapping has been used extensively across a variety of fields to advance and recommend research, ${ }^{18-21}$ educational methods, ${ }^{22}$ and healthcare approaches. ${ }^{23-25}$ It has also been used to create logic models for a national program, ${ }^{26}$ develop various state plans, ${ }^{27} 28$ and design chronic disease competencies. ${ }^{29}$ To our knowledge, this is the first use of concept mapping to identify priorities and inform future directions in support of diabetes translation research, considering health equity in diabetes prevention and treatment. It is critical to close the gap between evidence and real-world diabetes prevention and treatment to eliminate disparities in diabetes and achieve health equity. This requires ongoing support for researchers and community stakeholders engaged in the translation of science to practice and populations. ${ }^{30}$ There are several important findings from this work. 
Table 2 Statements with above average importance rating* by cluster

Statements by cluster

\section{Community and partner engagement $(n=11)$}

Conduct more community-engaged research addressing social context of diabetes prevention

Engage members of communities with high disease burden in the design and implementation of prevention and treatment solutions

Engage community stakeholders and residents using a community-engaged research process to identify critical areas

Partner with the community to raise awareness of both the health implications of diabetes and the simplicity of treatment

Include the patient population so they are equal partners in research, clinical care, outreach and long-term care

Be available to tribes when studies are done in their communities Incorporate pre-existing community programs that have had success

Work with local communities and tribes to understand and restore/develop local and indigenous food systems that are responsive to climate change

\section{Enrichment and capacity building $(n=12)$}

Engage clinics and the social service sector

Develop provider and researcher capacity for conducting community-engaged research and addressing social determinants

Ensure clear action steps to allow individuals and communities to benefit from research

Disseminate research findings to make leaders and members of society more aware of the societal costs of poor health access

Recruit and retain diverse physicians and researchers with experience working with communities impacted by diabetes

\section{Interventions for specific populations $(n=8)$}

Understand and implement strategies that are adapted to or tailored for communities that experience health disparities

Understand the diversity of individuals at risk for diabetes and their experiences 4.10 and perspectives

Create programs tailored to individual tribal communities

Build capacity and increase resources within communities of color

Focus on rural populations to build strategies that are sustainable/accessible in 4.00 those settings

Focus on reservation communities to build strategies that are sustainable and accessible in those settings

\section{Context specific interventions $(n=7)$}

Address diabetes prevention among young adults who are disproportionately at risk

Develop interventions and implementation strategies with vulnerable populations in mind

Assess whether commonly accepted treatments are having a positive effect on underrepresented populations

Address comorbidity with behavioral and mental health, especially in the context of low resources and limited access to care

Focus more on the unique social determinants in diverse communities

\section{Dissemination and implementation principles $(n=9)$}

Make sure data are reported by subgroups so comparisons can be made across research projects

\begin{tabular}{|c|c|c|}
\hline \multicolumn{2}{|c|}{ Average rating } & \multirow{2}{*}{$\begin{array}{l}\text { Priority } \\
\text { quadrant }\end{array}$} \\
\hline Importance & Feasibility & \\
\hline 4.08 & 3.76 & \\
\hline 4.17 & 3.82 & I \\
\hline 4.28 & 3.73 & I \\
\hline 4.18 & 3.90 & I \\
\hline 4.00 & 3.91 & I \\
\hline 4.00 & 3.77 & I \\
\hline 4.26 & 3.83 & I \\
\hline 4.38 & 4.04 & I \\
\hline 3.94 & 2.86 & II \\
\hline 3.87 & 3.80 & \\
\hline 4.06 & 3.86 & I \\
\hline 4.00 & 3.65 & I \\
\hline 3.94 & 3.68 & I \\
\hline 4.06 & 3.86 & I \\
\hline 4.38 & 3.60 & II \\
\hline 4.08 & 3.74 & \\
\hline 4.57 & 3.84 & I \\
\hline
\end{tabular}

$4.14 \quad$ I

$3.64 \quad$ II

$3.38 \quad$ II

$3.59 \quad$ II

3.50 II

$3.96 \quad 3.78$

4.00

3.88

4.15

\section{II}

II

II

4.22

3.82

3.82

3.33

II

4.22

3.48

II

3.96

3.79

3.94

4.00

I 


\section{Statements by cluster}

Focus on dissemination and implementation of culturally tailored diabetes prevention programs

Adopt a multidisciplinary approach

4.52

Focus on providing preventative healthcare

4.25

Address meaningful access to diabetes education, nutritionists, and so on (ie, 4.06 more than just a referral once at diagnosis from a physician)

\section{Nontraditional settings and strategies $(n=11)$}

3.62

Examine strategies to support patients between clinic appointments to achieve 4.00 treatment goals

\section{Cost and health economics $(n=6)$}

Emphasize dissemination and implementation of evidence-based treatments and programs

Study and measure the costs required to continue an effective intervention for longer than 24 months

\section{Innovative methods and metrics $(n=9)$}

Design studies to include implementation outcomes Include outcome measures around disparities

\section{Policy approaches $(n=11)$}

\subsection{6}

3.65

4.18

4.18

4.24

3.75

3.55

Priority quadrant +

Disseminate research findings to influence health policy

4.00

3.48

I

Have direct implications on practice, research, and policy

3.71

3.93

Focus on societal/policy changes that can impact diabetes risk

4.00

4.36

4.05

4.60

4.03

3.10

Inform an overhaul of the US healthcare system to provide affordable, transparent, trustworthy, and high quality access to all people

Map the policy context that perpetuate disparities and incorporate into planning for interventions

Find a way to reduce costs, especially for medication

4.42

4.13

4.17

3.43

4.22

3.19

4.24

2.05

\section{I}

\section{I}

II

Fund more research that budgets for implementation that is in line with realworld costs for future implementation

$3.94 \quad 3.52 \quad$ II

$\begin{array}{lll}4.00 & 2.60 & \text { II } \\ 4.17 & 3.36 & \text { II }\end{array}$

\section{Next generation interventions $(n=11)$}

Take into account comorbidity and overall care of individuals with multiple, complex diagnoses, conditions

\section{Incorporate the broader contributors to unhealthy behaviors and lifestyles and} work to address these in unison with clinical approaches

\section{Address root causes at patient and provider levels}

Study the effectiveness of simple, inexpensive, scalable interventions to influence health behaviors, particularly among medically underserved or

3.94

3.94

4.06

4.06

4.22

2.71

3.42

4.00

3.62

II

4.11

Identify affordable healthy living strategies for the poor and working population

Find ways to address the social determinants of diabetes and related health disparities

Understand better the pathways by which socioeconomic status disparities drive diabetes

Bold values indicate cluster-level average ratings.

*Mean importance rating=3.91.

†Priority quadrant I characterized by importance $\geq 3.91$, feasibility $\geq 3.65$, quadrant II characterized by importance $\geq 3.91$, feasibility $\leq 3.65$.

First, the 10 stakeholder-derived clusters describe future translational research priorities in support of the mission of the WU-CDTR, charged with supporting investigators conducting diabetes translation research. These results create a framework to guide future research efforts, first by reinforcing the importance of two ongoing 


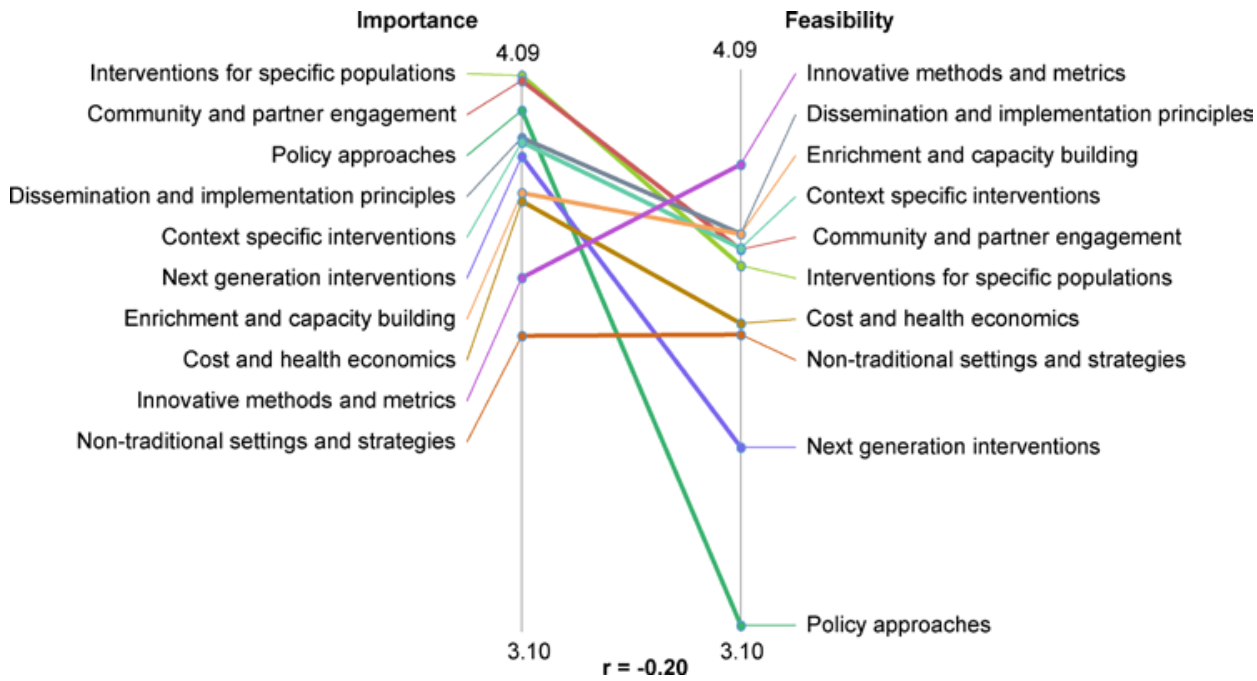

Figure 2 Cluster pattern match by importance and feasibility.

efforts (1) working synergistically with complimentary programs to ensure enhanced educational experiences (enrichment and capacity building) and (2) promoting community-academic partnerships to facilitate research that aligns with community needs (community and partner engagement). To ensure a program is effective and sustainable, it is critical that the program is tailored to fit the needs of diverse populations and community settings. ${ }^{31}$ Results describe several considerations when developing and implementing interventions, including the importance of adapting and testing interventions in specific populations and designing efforts with context in mind (interventions for specific populations and context specific interventions). Specific tools and methods at the researchers' disposal are described and outlined in dissemination and implementation principles, innovative methods and metrics, nontraditional settings and strategies, and cost and health economics. These methods and strategies are needed to produce evidence of value to researchers and to decision makers in real-world settings. Last, stakeholders identified macrolevel themes and strategies crucial for moving the field forward and advancing efforts to achieve health equity (next generation interventions and policy approaches). These particular clusters included strategies that move from compensatory (ie, immediate, individually focused actions to prevent and manage diabetes) to noncompensatory approaches (ie, directly taking actions to impact social determinants of health as root causes of disparities) to address health equity. ${ }^{3}$

Second, in addition to defining a framework, this study provides guidance for acting and targeting finite resources toward diabetes translation research by capturing the

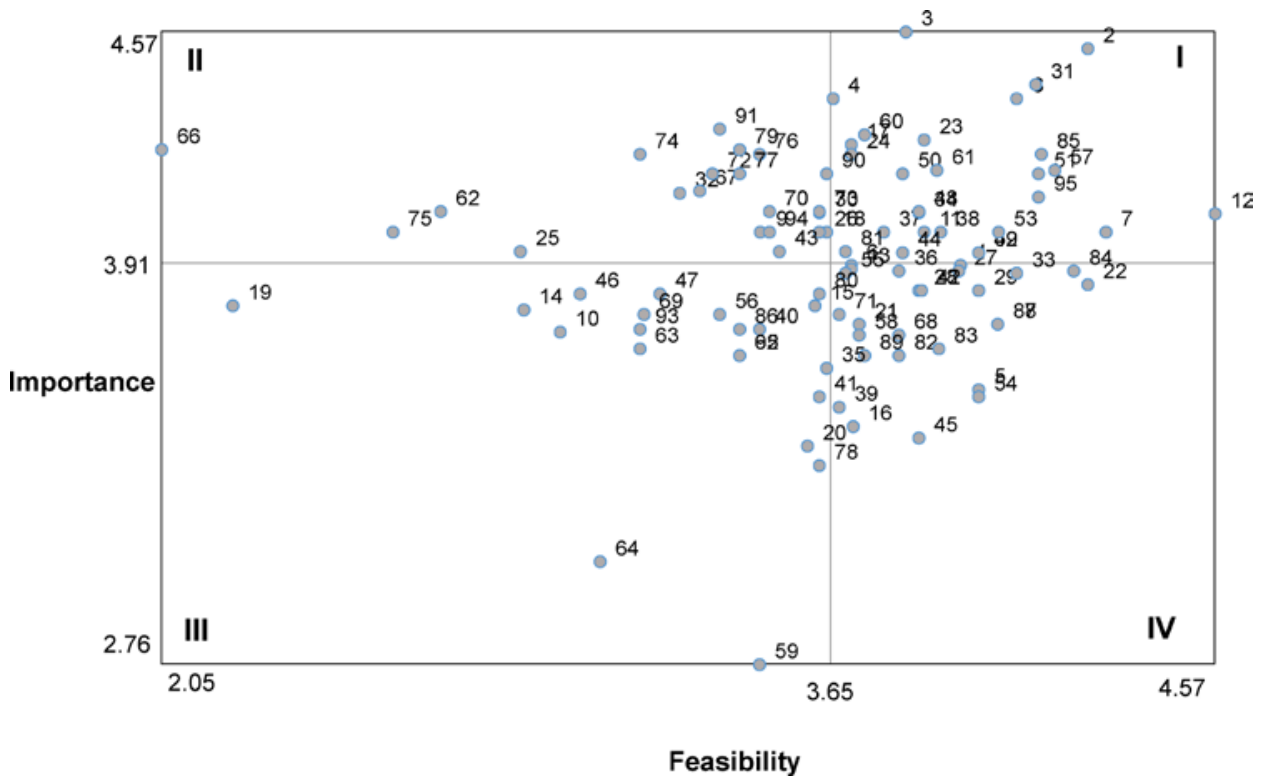

Figure 3 Priority quadrants: statements plotted by average importance and feasibility. Priority quadrants are delineated by above or below average rating for importance (3.91) and feasibility (3.65). Quadrants include: (I) high importance/high feasibility (go-zone); (II) high importance/low feasibility (innovative-targets); (III) low importance/high feasibility and (IV) low importance/low feasibility. 
importance and feasibility of proposed statements. Statements and clusters found in the "go-zone," above average importance and feasibility, describe actionable priorities that can and should currently be addressed in support of diabetes translation research (community and partner engagement, enrichment and capacity building, and dissemination and implementation principles). Since these items are rated highly feasible, they are considered "low-hanging fruit," providing the basis for current work to evaluate the extent to which these themes are being supported and what needs to be done to assure ongoing or growing support.

Finally, this study identified future priorities through the "innovative-targets", which included items deemed important, but less feasible. The clusters with the largest number of statements in this quadrant included interventions for specific populations, next generation interventions, and policy approaches. A common thread among these innovative targets is that they address the importance of diversity, multisector approaches, and macrolevel research. While identified as influential in achieving health equity, there is less clarity around how to accomplish this work. To facilitate growth of the field, it is critical to expand support for actions that are deemed important but less feasible by stakeholders. The WU-CDTR, and similar institutions, could play an important strategic role in assuring resources for high quality research to address these innovative targets.

\section{Limitations}

Despite the benefits of the participatory nature of the concept mapping process, there are several limitations to this approach. First, the process is time intensive for participants, especially for the sorting and rating activities, potentially affecting rates of participation. While participation rates met recommended guidelines, ${ }^{13}$ there were not enough nonacademic participants to complete subgroup comparisons. Although we recruited from a national network of researchers and public health practitioners, the homogeneity of participants may limit the scope of results. In addition, the focus on research may have dissuaded nonresearch focused individuals from participating. While important for sorting and rating stages of the study, reducing the number of statements from 119 to 95 may have resulted in less specificity between statements. Variability in responses for feasibility and importance was relatively narrow, which may limit interpretation of differences between statements and clusters. Finally, this study took place in the USA and the findings may not all be applicable to other geographical regions.

\section{CONCLUSION}

This study used the concept mapping methodology and a national network of diabetes researchers and public health practitioners to create a framework of 10 priority areas to guide future priorities in diabetes translation research to achieve health equity. Statements and clusters were rated on importance and feasibility, providing further guidance for evaluation and planning. Themes rated as highly important and feasible provide the basis to evaluate current research efforts. Future efforts and research should explore how to best support innovativetargets, themes rated highly important but less feasible, to advance the field of diabetes translation research.

Acknowledgements The authors thank the participation for their time and input, as well as the WU-CDTR Executive Committee and others for their input on refining the research question and focus prompt.

Contributors AP collected and analyzed data, drafted the manuscript, and created all tables and figures. SJ assisted with data cleaning and drafting and revising manuscript. RGT and SM provided guidance on study methods and manuscript revisions. DH-J provided overall scientific oversight and conception of project, drafted and revised manuscript. All authors interpreted results and approve the final published manuscript.

Funding This work was supported by the Washington University in St. Louis CDTR (Grant Number P30DK092950 from the NIDDK).

Disclaimer The content is solely the responsibility of the authors and does not necessarily represent the official views of the CDTR or NIDDK.

Competing interests None declared.

Patient consent for publication Not required.

Provenance and peer review Not commissioned; externally peer reviewed.

Data availability statement Data are available on reasonable request.

Open access This is an open access article distributed in accordance with the Creative Commons Attribution Non Commercial (CC BY-NC 4.0) license, which permits others to distribute, remix, adapt, build upon this work non-commercially, and license their derivative works on different terms, provided the original work is properly cited, appropriate credit is given, any changes made indicated, and the use is non-commercial. See: http://creativecommons.org/licenses/by-nc/4.0/.

ORCID iDs

Allison Phad http://orcid.org/0000-0003-4373-8817

Rachel G Tabak http://orcid.org/0000-0003-2967-3906

\section{REFERENCES}

1 Centers for Disease Control and Prevention. National diabetes statistics report, 2017. Atlanta, GA: Centers for Disease Control and Prevention, US Department of Health and Human Services, 2017.

2 Gaskin DJ, Thorpe RJ, McGinty EE, et al. Disparities in diabetes: the nexus of race, poverty, and place. Am J Public Health 2014; 104:2147-55.

3 Haire-Joshu D, Hill-Briggs F. The next generation of diabetes translation: a path to health equity. Annu Rev Public Health 2019;40:391-410.

4 Kumanyika SK. A framework for increasing equity impact in obesity prevention. Am J Public Health 2019:e1-8.

5 Chinman M, Woodward EN, Curran GM, et al. Harnessing implementation science to increase the impact of health equity research. Med Care 2017;55:S16-23.

6 Haire-Joshu DL. Next steps: eliminating disparities in diabetes and obesity. Prev Chronic Dis 2015;12:E71.

7 Harris JK, Wong R, Thompson K, et al. Networks of collaboration among scientists in a center for diabetes translation research. PLOS One 2015;10:e0136457.

8 National Institutes of Health. NIDDK centers for diabetes translation research (P30), 2015. Available: https://grants.nih.gov/grants/guide/ rfa-files/RFA-DK-15-003.html

9 Brownson RC, Kelly CM, Eyler AA, et al. Environmental and policy approaches for promoting physical activity in the United States: a research Agenda*. Journal of physical activity health 2008;5:488-503.

10 Johnson DB, Quinn E, Sitaker M, et al. Developing an agenda for research about policies to improve access to healthy foods in rural communities: a concept mapping study. BMC Public Health 2014;14:592. 
11 Wutzke S, Roberts N, Willis C, et al. Setting strategy for system change: using concept mapping to prioritise national action for chronic disease prevention. Health Research Policy and Systems 2017;15.

12 Waltz TJ, Powell BJ, Matthieu MM, et al. Use of concept mapping to characterize relationships among implementation strategies and assess their feasibility and importance: results from the expert recommendations for implementing change (ERIC) study. Implementation Science 2015;10.

13 Kane M, Trochim WMK. In: Bickman L, Rog DJ, eds. Concept mapping for planning and evaluation. Thousand Oaks, California: SAGE Publications, 2007: 199.

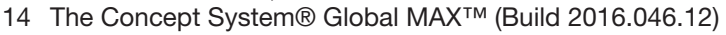
[Web-based Platform]. (2016). Ithaca, NY. Available: http://www. conceptsystemsglobal.com

15 Diabetes Prevention Program Research Group. Long-term effects of lifestyle intervention or metformin on diabetes development and microvascular complications over 15-year follow-up: the diabetes prevention program outcomes study. Lancet Diabetes Endocrinol 2015;3:866-75.

16 Kruskal JB, Wish M. Multidimensional scaling. 1978 2019/07/12. In: Basic Concepts of Multidimensional Scaling [Internet]. Thousand Oaks, California: SAGE Publications, Inc. https://methods.sagepub. com/book/multidimensional-scaling

17 Rosas SR, Kane M. Quality and rigor of the concept mapping methodology: a pooled study analysis. Eval Program Plann 2012;35:236-45

18 Anderson LA, Day KL, Vandenberg AE. Using a concept map as a tool for strategic planning: the healthy brain initiative. Preventing chronic disease 2011;8.

19 van Bon-Martens MJH, van de Goor IAM, van Oers HAM. Concept mapping as a method to enhance evidence-based public health. Eval Program Plann 2017;60:213-28.

20 Vaughn LM, Jones JR, Booth E, et al. Concept mapping methodology and community-engaged research: a perfect pairing. Eval Program Plann 2017;60:229-37.
21 Powell BJ, Stanick CF, Halko HM, et al. Toward criteria for pragmatic measurement in implementation research and practice: a stakeholder-driven approach using concept mapping. Implementation Science 2017;12.

22 Soellner R, Lenartz N, Rudinger G. Concept mapping as an approach for expert-guided model building: the example of health literacy. Eval Program Plann 2017;60:245-53.

23 Stankov I, Howard N, Daniel M, et al. Policy, research and residents' perspectives on built environments implicated in heart disease: A concept mapping approach. Int J Environ Res Public Health 2017;14:170.

24 Lhussier M, Eaton S, Forster N, et al. Care planning for longterm conditions - a concept mapping. Health Expectations 2015;18:605-24.

25 Ogden K, Barr J, Greenfield D. Determining requirements for patientcentred care: a participatory concept mapping study. BMC Health Serv Res 2017;17:780.

26 Anderson LA, Gwaltney MK, Sundra DL, et al. Using concept mapping to develop a logic model for the prevention research centers program. Prev Chronic Dis 2006;3:A06.

27 Trochim WMK, Milstein B, Wood BJ, et al. Setting objectives for community and systems change: an application of concept mapping for planning a statewide health improvement initiative. Health Promot Pract 2004;5:8-19.

28 Wheeler FC, Anderson LA, Boddie-Willis C, et al. The role of state public health agencies in addressing less prevalent chronic conditions. Prev Chronic Dis 2005;2:A12.

29 Slonim A, Wheeler FC, Quinlan KM, et al. Designing competencies for chronic disease practice. Preventing chronic disease 2010;7:A44-A.

30 Fort DG, Herr TM, Shaw PL, et al. Mapping the evolving definitions of translational research. J Clin Trans/ Sci 2017;1:60-6.

31 Nierkens V, Hartman MA, Nicolaou M, et al. Effectiveness of cultural adaptations of interventions aimed at smoking cessation, diet, and/ or physical activity in ethnic minorities. A systematic review. PLOS One 2013;8:e73373. 